\title{
El principio non bis in idem en la Ley de Tránsito 18.290: Comentarios a la jurisprudencia del Tribunal Constitucional
}

\author{
The principle non bis in idem in Traffic Law 18.290: \\ Comments to the jurisprudence of Constitutional Court
}

Rodrigo Alejandro Henríquez Figueroa

Pontificia Universidad Católica de Valparaíso, Chile

\begin{abstract}
RESUMEN El presente trabajo tiene por objeto analizar, desde una perspectiva dogmática y práctica, la interpretación por parte de los operadores jurídicos de dos conjuntos de normas previstas en la Ley 18.290 o Ley de Tránsito, cuya aplicación pudiese vulnerar la garantía de los particulares frente al ius puniendi estatal denominada non bis in idem o prohibición de doble sanción por un mismo hecho, entre otras garantías relacionadas con el debido proceso. Asimismo, se expondrán algunos comentarios con base en las diversas sentencias dictadas por el Tribunal Constitucional en los últimos años, en específico respecto de la aplicación del artículo 207 letra b) de la Ley de Tránsito.
\end{abstract}

PALABRAS CLAVE Ley de Tránsito, non bis in idem, debido proceso, licencia de conducir, acumulación de infracciones, seguridad vial.

ABSTRACT This study aims to analyze, from a dogmatic and practical perspective, the interpretation by legal operators of two set of rules established in the Law 18.290 or Traffic Law, whose application could violate the guarantee of citizens front the ius puniendi of the State known as non bis in idem or prohibition of double punishment for a same fact, among other guarantees related with the due process. They will also be proposed some comments based on various rulings handed down by the Constitutional Court in recent years, in particular regarding the application of article 207 b) of the Traffic Law.

KEYWORDS Traffic Law, non bis in idem, due process, driver license, accumulation of infringements, road safety. 


\section{Introducción}

En el presente trabajo se plantearán algunas consideraciones sobre dos conjuntos de normas o articulados previstos en la Ley de Tránsito que al ser aplicadas por los operadores jurídicos vulnerarían la garantía frente al poder punitivo estatal, denominada non bis in idem o prohibición de doble sanción con base en un mismo hecho:

Conforme a este principio se procura impedir que un hecho que ya ha sido sancionado o que ha servido de base para la agravación de una pena, sea utilizado nuevamente con ese fin (Bustos Ramírez, 2007: 370).

De este modo, si un hecho ya ha sido tomado en consideración para la aplicación de una pena o circunstancia modificatoria de responsabilidad penal, no es lícito volver a tenerlo en cuenta por segunda vez o ulterior vez para los mismos efectos (Etcheberry, 1997: 108).

La finalidad de este principio es la seguridad y certeza, no solo del administrado sino del sistema jurídico en su conjunto, de que el hecho por el cual ha sido sancionado o procesado no sea revisado de nuevo por el Estado, en dos o incluso en más ocasiones, en el mismo proceso o en otro futuro y dentro de una misma jurisdicción (Ramírez Torrado, 2013: 4).

Asimismo, se esbozarán algunos comentarios, con base en la reciente jurisprudencia del Tribunal Constitucional, respecto de las dos posturas adoptadas por los ministros sobre la aplicación del artículo 207 letra b) de la Ley de Tránsito.

La primera de las normas objeto de estudio es la prevista en el artículo 207 letra b) de la Ley de Tránsito, que señala:

Sin perjuicio de las multas que sean procedentes, el juez decretará la suspensión de la licencia de conducir del infractor, en los casos y por los plazos que se indican a continuación: [...] b) Tratándose de procesos por acumulación de infracciones, al responsable de dos infracciones o contravenciones gravísimas cometidas dentro de los últimos doce meses, la licencia se le suspenderá de 45 a 90 días y al responsable de dos infracciones o contravenciones graves cometidas dentro de los últimos doce meses, de 5 a 30 días.

Como complemento de la referida norma, es necesario mencionar lo dispuesto en el artículo 216 del mismo cuerpo legal, que señala:

En los casos en que por acumulación de infracciones gravísimas o graves en el registro, apareciera que se cumplen los presupuestos legales para que opere la suspensión o cancelación de la licencia de un conductor, el Servicio de Registro Civil e Identificación deberá informarlo detalladamente al juez de policía local del domicilio que el titular de la licencia tuviera registrado, dentro de los dos días hábiles contados desde la anotación de la infracción en el registro.

Pues bien, es respecto de la aplicación en concreto de la primera norma transcrita que el Tribunal Constitucional se ha pronunciado, en sede de inaplicabilidad, en múlti- 
ples oportunidades, acogiendo los requerimientos en algunas y rechazándolos en otras, pero en general, siempre con prevenciones o votos disidentes. ${ }^{1}$

El segundo conjunto de preceptos normativos que serán objeto de algunos comentarios, en orden a que su aplicación quebrantaría el principio non bis in ídem, son los previstos en el artículo 16, en relación al artículo 13 numeral 1 y artículo 14 letras a) y b) numeral 1, todos de la Ley de Tránsito, los cuales establecen los requisitos para la obtención de licencias de conducir, y en lo que nos interesa, se establece como condición indispensable para obtener licencia de conducir no profesional la obligación de acreditar la «idoneidad moral» del solicitante.

Los dos conjuntos de normas anteriormente mencionados se introdujeron por la Ley 19.495, que «Modificó la Ley 18.290 de Tránsito en lo relativo a la obtención de licencias de conducir», publicada el 8 de marzo de 1997 y vigente desde el 20 de enero de 2001.

\section{Constitucionalidad del artículo 207 letra b): Planteamiento}

El problema que ha suscitado la aplicación de la referida norma consiste en la hipótesis fáctica de que, dentro de los últimos doce meses, un único conductor fuere fiscalizado, denunciado y sancionado en dos oportunidades distintas por la comisión sucesiva de dos infracciones graves o gravísimas a la Ley de Tránsito y, no obstante que por cada una de ellas ya le fue impuesta una sanción de multa o suspensión de licencia, ${ }^{2}$ sin reiterarse una nueva acción voluntaria de su parte, necesariamente y por tercera vez volverá a ser citado ante la presencia judicial, órgano que tiene el imperativo legal de suspender nuevamente, o incluso cancelar, su licencia de conducir, dependiendo de si se cumplen o no los presupuestos legales que ameriten la imposición de esta nueva sanción.

El Tribunal Constitucional ha entendido que el problema en la situación anterior consiste en que una persona pueda verse expuesta a sufrir tres sanciones por dos conductas ilícitas, pues si comete dos infracciones graves o gravísimas, cada una de ellas será sancionada en su respectiva ocasión con pena de multa y/o suspensión de licencia, y en seguida, sin que medie nueva y autónoma conducta reprochable, y por el solo

1. En reiteradas ocasiones en que el Tribunal Constitucional ha resuelto rechazar los requerimientos de inaplicabilidad presentados sobre el artículo 207 letra b) de la Ley de Tránsito, tal determinación así ha sido declarada solo por no reunirse en dicha sede los quórums mínimos exigidos al efecto por ley para acoger dicha acción, toda vez que en los procesos iniciados por acciones de inaplicabilidad por inconstitucionalidad no resulta dirimente el voto del ministro presidente de la sala, por lo que frente a un empate de votos, se opta por rechazar el requerimiento, lo que evidencia una ausencia de consenso en torno a la materia (sentencias del Tribunal Constitucional, roles 1960-11, 1961-11, 2018-11 y 2108-11, todas de 2011).

2. El mismo artículo 207 letra a) de la Ley de Tránsito obliga al juez a imponer, además de la pena de multa, la de suspensión de licencia de conducir, en caso de infracciones o contravenciones gravísimas, por un lapso de 5 a 45 días. En el caso de infracciones o contravenciones graves, cuando se trata de la primera infracción, procede solo sanción pecuniaria; no obstante, y en caso de incurrir el mismo infractor en una nueva contravención grave, el artículo 204 inciso segundo, párrafo final, le permite al juez, a propósito de esta segunda contravención, aplicar una multa aumentada y suspender la licencia de conducir. 
hecho de que las anteriores infracciones fueron cometidas dentro de los últimos doce meses, deberá imponerse forzosamente al infractor una tercera sanción o castigo de suspensión de licencia. ${ }^{3}$

$\mathrm{Al}$ respecto, numerosos han sido los pronunciamientos por parte de la magistratura constitucional, lo que evidencia los altos niveles de ocurrencia de la referida hipótesis. En general, los ministros que dictaron las sentencias objeto de estudio determinaron acoger o rechazar los requerimientos, por las razones explicadas a continuación. ${ }^{4}$

\section{Por acoger los requerimientos}

Esta postura (sentencias roles 2045-11, 2254-12, 2896-15 y 3.00o-16 de 2011, 2012, 2015 y 2016 respectivamente) sostiene que la aplicación en concreto del artículo 207 b) de la Ley de Tránsito en las gestiones judiciales pendientes sería contraria a la Constitución, con base en los siguientes argumentos.

\section{Problemas de tipicidad en la descripción de la conducta}

Este primer argumento descansa en el hecho de que la tercera sanción impuesta por incurrir el infractor en acumulación de infracciones no encuentra su correlativo en acciones o comportamientos típicos satisfactorios, concurriendo el poder punitivo estatal sin una acción u omisión que lo sustente, hipótesis que se encuentra proscrita según el artículo 19 numeral 3 de la Carta Fundamental.

Señala al respecto la magistratura constitucional que

se vulneraría la garantía de la tipicidad de la conducta y que consiste en que ninguna ley podrá establecer penas sin que la conducta que se sanciona esté expresamente descrita en ella. Lo anterior, considerando que la tipicidad, como descripción abstracta de una circunstancia delictiva, es un elemento esencial del delito, sin el cual, éste simplemente no existe, por lo que al no concurrir algún comportamiento o conducta, entendida como un acto voluntario, no se realiza ninguna acción que permita configurar un hecho típico (sentencia del Tribunal Constitucional, rol 2896-15, 2015, voto de mayoría, considerando vigésimo primero).

El profesor Cordero Quinzacara, en relación con este principio y su aplicación al derecho administrativo sancionador, sostiene:

3. Sentencia del Tribunal Constitucional, rol 300o-16, 2016, voto de mayoría por acoger requerimiento, considerando quinto.

4. En favor de acoger los diversos requerimientos de inaplicabilidad del artículo 207 b) de la Ley de Tránsito, en la mayoría de los casos, concurrieron los ministros Iván Aróstica M., Domingo Hernández E., Enrique Navarro B., Hernán Vodanovic E., Cristian Letelier A., José Antonio Viera G., Juan José Romero G. y José Ignacio Vásquez M. Por el contrario, en favor de rechazar los diversos requerimientos de inaplicabilidad del artículo 207 b) de la Ley de Tránsito, en la mayoría de los casos, concurrieron los ministros Carlos Carmona S., Marisol Peña T., Gonzalo García P., Francisco Fernández F. y Raúl Bertelsen R. 
Si bien en el ámbito penal se discute si el fundamento del principio de tipicidad se debe encontrar en la certeza subjetiva que éste debe otorgar a los ciudadanos, o de una garantía normativa que reserva al legislador la determinación de las conductas punibles, lo cierto en que en sede administrativa la tipicidad cumple esta doble función. Por una parte, dada la complejidad de las materias, conductas y deberes que se imponen en el ámbito administrativo, es necesario que los particulares tengan certeza de los mismos con el objeto de adecuar su conducta a lo exigido por la autoridad para no incurrir en infracción. Al mismo tiempo, dicha conducta es en principio legítima, salvo que el propio legislador determine que debe ser prohibida y sancionada, cuestión de estricta reserva legal (Cordero Quinzacara, 2014: 243).

Por tanto, en la sanción por acumulación de infracciones al tránsito no existe una descripción clara de la acción u omisión en la que incurre el infractor y que amerite la imposición de una nueva consecuencia punitiva, más allá de las impuestas y cumplidas in actum en los procesos infraccionales que dieron origen a esta tercera sanción por acumulación de infracciones, la que finalmente se aplicará como consecuencia de una conducta atípica.

\section{La sanción por acumulación de infracciones de tránsito vulnera la garantía del non bis in idem}

En los fallos arriba señalados, el Tribunal Constitucional determinó que todas las normas infringidas en los procesos infraccionales vinculados entre sí protegían un mismo bien jurídico consistente en un interés colectivo o valorado, entendido como la seguridad vial y de tránsito, compartiendo las conductas y su sanción el mismo fundamento jurídico, lo que unido a la identidad de hechor (subjetiva) y de objeto normativo (fáctica), constituyen los elementos para que la garantía en cuestión surta plenos efectos.

Resulta palmario, en este sentido, lo señalado en la prevención del ministro Juan José Romero Guzmán, en uno de los pronunciamientos, quien concurrió por acoger el requerimiento, previniendo que

En este caso, una conducta, constitutiva de una infracción del tránsito por exceso de velocidad, es sancionada, luego tenida como agravante de un segundo hecho similar y, por último, sancionada nuevamente (incluso con niveles de severidad potencialmente mayores) sin mediar la comisión de hecho infraccional alguno (sentencia del Tribunal Constitucional, rol 2896-15, 2015, prevención del ministro Juan José Romero, considerando tercero). ${ }^{5}$

5. En el mismo considerando de su prevención, el ministro Romero se cuestiona: «¿Puede la reincidencia considerarse o valorarse más allá de una circunstancia agravante de responsabilidad, dando lugar, además, y sin haberse cometido un nuevo hecho infraccional, a una segunda sanción de severidad incluso mayor? La respuesta es que no es constitucionalmente posible, ya que vulneraría el principio ne bis in idem, el cual puede concebirse como un estándar mínimo de racionalidad y justicia procesal y, por ende, como un límite a la configuración legislativa del ius puniendi del Estado». 
En consecuencia, se consideraron como un mismo hecho, consistentes en infracciones graves o gravísimas a la Ley de Tránsito, la primera de ellas sancionada con una multa y una suspensión de licencia de conducir, en caso de infracción gravísima, o solo multa, en caso de infracción grave, la cual fue cumplida de inmediato por el infractor, y que luego, no solo será susceptible de ser considerada como una circunstancia modificatoria de responsabilidad de una segunda infracción de similares características, y por la cual se aplicará nuevamente una sanción, sino que además, esta primera infracción servirá de base esencial y necesaria, junto con la segunda, de una nueva hipótesis de punición.

\section{La sanción por acumulación de infracciones vulnera la prohibición de presumir de derecho la responsabilidad penal6}

Preliminarmente, cabe señalar que este principio emana de la dignidad humana, del derecho a defensa dentro de un debido proceso y del principio de presunción de inocencia, todas garantías esenciales para la configuración de un Estado de derecho y que resguardan los derechos de los particulares frente a la actividad punitiva estatal.

El Tribunal Constitucional ha sostenido en relación con esta materia que

habrá presunción de derecho de delitos cuando ella se formule respecto del hecho constitutivo de delito, al grado de participación o a la responsabilidad, impidiendo al imputado demostrar su inocencia con los medios de prueba contemplados por la ley, ya que para atribuir responsabilidad por un hecho delictual, se deben previamente acreditar los elementos constitutivos del mismo: conducta, tipicidad, culpabilidad y antijuridicidad (sentencia del Tribunal Constitucional, rol 825-07, 2007, considerando vigésimo cuarto). ${ }^{7}$

En la hipótesis en estudio se verifica la transgresión de este principio, ya que el legislador le atribuye responsabilidad infraccional o contravencional a un sujeto por el solo hecho de haber sido previamente sancionado en un determinado periodo de tiempo, prescindiendo de la culpabilidad o atribución subjetiva de una conducta típica, antijurídica y culpable. Lo anterior deriva en una imposibilidad para el infractor de poder desvirtuar los supuestos de hecho y los presupuestos legales que fundamentan su responsabilidad, lo que es inconstitucional, ya que al no ser posible desvirtuar la imputación y considerando que no existe una conducta infraccional descrita correctamente, se vulnera la prohibición de presumir la responsabilidad penal, introduciéndose una excepcional hipótesis de responsabilidad infraccional objetiva en la Ley de Tránsito, lo que violenta, además de las garantías ya enunciadas, la igual protección de la ley en

6. En la especie resultaría más adecuado usar la terminología de prohibición de presumir de derecho la responsabilidad contravencional o infraccional, en lugar de responsabilidad penal, atendida la naturaleza administrativa de la infracción y la magnitud de su sanción.

7. En este mismo sentido, sentencia del Tribunal Constitucional rol, 2045-11, 2011, considerando séptimo. 
el legítimo ejercicio de los derechos del infractor y el derecho a un igual acceso a la justicia. En otras palabras, se trata de un prejuzgamiento respecto de la conducta y la sanción, imposible de desvirtuar para el infractor.

Lo grave en el supuesto de esta presunción es que se le impide a los jueces de la instancia adentrarse en los elementos subjetivos de la conducta del imputado, pues éstos están determinados por la ley que crea las figuras contravencionales, la objetividad incontrastable de sentencias condenatorias cumplidas y acumuladas.

\section{La sanción por acumulación de infracciones vulnera el principio de proporcionalidad de las sanciones o penas}

En términos simples, la pena o sanción consiste en un elemento de naturaleza disuasiva y retributiva, que permite al Estado propender a la protección de bienes jurídicos de relevancia individual y colectiva. No obstante, para la consecución de lo anterior, el Estado no goza de plena libertad, sino que debe respetar ciertos principios universales en el ejercicio de su potestad sancionatoria, como son el principio de intervención mínima, prohibición de la arbitrariedad y proporcionalidad.

La proporcionalidad puede ser entendida con una retribución justa y equitativa entre la conducta infraccional y la sanción aplicada. El profesor Mario Garrido Montt sostiene que

La sanción debe ser proporcional a la gravedad del hecho, a las circunstancias individuales de la persona que lo realizó y a los objetivos político criminales perseguidos. La pena será proporcional a las condiciones que la hacen necesaria y que en ningún caso pueden exceder dicha necesidad (Garrido Montt, 2007: 49).

La proporcionalidad de la pena implica la concreción de una igual protección de derechos, tanto en su vertiente de igualdad jurídica como de fundamento por antonomasia de un justo y racional procedimiento. El Tribunal Constitucional chileno ha estimado que

La proporcionalidad de las sanciones es un atributo esencial del cual no puede prescindirse, y en la especie, por la comisión de un mismo hecho se sanciona en más de una oportunidad al responsable, y muy en particular, si a las penas impuestas por dos infracciones diversas se le adiciona necesariamente una suspensión de licencia de conducir (sentencia del Tribunal Constitucional, rol 2108-11, 2011, voto disidente por acoger requerimiento, considerando octavo).

En España, los profesores Irene Nuño Jiménez y Francisco Puerta Seguido señalan en este mismo sentido que

El principio de proporcionalidad debe ser observado por el legislador a la hora de formular la relación entre las infracciones y las sanciones, ya sea para clasificarlas según su gravedad o para concretar qué sanción le corresponde a cada modalidad de infracciones, como dispone el artículo 131.3 LRJPAC: «Se deberá guardar la debida 
adecuación entre la gravedad del hecho constitutivo de la infracción y la sanción» que sea de aplicación. Si este principio no es aplicado a la hora de regular la relación entre infracciones y sanciones determinará la inconstitucionalidad de la ley sancionadora (Nuño Jiménez y Puerta Seguido, 2016: 160).

En este mismo orden de ideas, el Tribunal Constitucional español se ha pronunciado respecto de la proporcionalidad de las sanciones, indicando que

Aplicada una determinada sanción a una específica infracción, la reacción punitiva ha quedado agotada. Dicha reacción ha tenido que estar en armonía con la acción delictiva, y la correspondiente condena ha de considerarse como autosuficiente desde una perspectiva punitiva, por lo que aplicar otra sanción en el mismo orden punitivo representaría la ruptura de esa proporcionalidad, [...] una sanción desproporcionada respecto a la infracción cometida (sentencia del Tribunal Constitucional de España, rol 154-90, 15 de octubre de 1990, foja 3).

Por último, el constitucionalista Nogueira Alcalá destaca que

El principio de proporcionalidad se encuentra subsumido en el ordenamiento constitucional chileno en la garantía genérica de los derechos establecida constitucionalmente en las bases de la institucionalidad que dan forma al Estado de derecho (artículos 6 y 7), en el principio de prohibición de conductas arbitrarias (artículo 19 numeral 2) y en la garantía normativa del contenido esencial de los derechos (artículo 19 numeral 26 de la Constitución), además del valor justicia inherente al derecho (Nogueira Alcalá, 2010: 374).

En conclusión, al aplicarse una sanción por acumulación de infracciones, según lo dispone el artículo 207 letra b) de la Ley de Tránsito, se vulneraría flagrantemente el principio de proporcionalidad, ya que a las dos sanciones impuestas por las infracciones originales se les adiciona una tercera sanción, consistente en la suspensión o cancelación de licencia de conducir, sin considerar los pormenores de las conductas que originaron las contravenciones preliminares, o bien, sin evaluar si las circunstancias o antecedentes personales del infractor revelen una real y especial peligrosidad que amerite la imposición de una nueva sanción. Situación que empeora para el infractor si se considera el carácter imperativo en la redacción de la norma, en cuanto ésta obliga al juez a imponer la sanción de suspensión o cancelación de licencia de conducir, lo que se traducirá finalmente en la imposibilidad para el infractor de seguir desplazándose libre e independientemente por las vías públicas sobre un vehículo motorizado, lo que limita así, de manera injusta y arbitraria, la garantía de la libertad ambulatoria prevista en el artículo 19 numeral 7 de la Constitución.

\section{Por rechazar los requerimientos}

Esta postura (sentencias del Tribunal Constitucional roles 1804-10, 1960-11, 1961-11 y 2402-13, de 2010, 2011 y 2013 respectivamente) esgrime que la aplicación del precepto en cuestión no vulneraría la Carta Fundamental, ni ninguno de los principios enunciados 
en el apartado anterior, primeramente en consideración al especial tratamiento que tiene la licencia de conductor para el interés social y, en segundo lugar, debido a que la sanción por acumulación de infracciones, en estricto rigor, no vulnera el principio non bis in idem por no verificarse el requisito de la triple identidad para la operatividad del mismo.

\section{Especial tratamiento de la licencia de conducir}

\section{Comienzan su argumento indicando que}

La licencia de conducir es una manifestación de la libertad individual del ser humano, en su vertiente de la libertad ambulatoria o de desplazamiento, lo que se traduce en la posibilidad de movilizarse libremente de un lugar a otro en vehículos motorizados, circulando por las vías públicas del territorio nacional. Por tanto, resulta habitual que al tratarse de una garantía constitucional, sea necesario desarrollar y concretar su contenido mediante una regulación legal que permita establecer restricciones o condiciones en su ejercicio, debiendo respetarse, en todo caso, el contenido esencial de dicha libertad (sentencia del Tribunal Constitucional, rol 2402-13, 2013, voto por rechazar requerimiento, considerando noveno) ${ }^{8}$

La justificación anterior reside en que la conducción en las vías públicas es una actividad que genera riesgos para bienes materiales y personales de terceros. Agrega esta postura que, debido a ello, la licencia de conducir consiste en un acto administrativo de autorización, municipal, habilitante, de vigencia indefinida, pero de revisión temporal, que puede ser denegada, suspendida o cancelada, en caso de concurrir las hipótesis y presupuestos previstos en la ley.

Otro ejemplo del carácter riesgoso que le asigna el legislador a la conducción de vehículos motorizados en las vías públicas es la obligatoriedad de todo propietario de un automóvil de contratar un seguro obligatorio de accidentes personales causados por vehículos motorizados, de conformidad al artículo 1 de la Ley 18.490.

Finalizan esta idea indicando que mantener indemne el perjuicio a terceros constituye un elemento angular para determinar el nivel de intervención regulatoria de la actividad punitiva estatal, lo que se conoce como el "principio de no daño» y que, precisamente, el derecho del tránsito se erige sobre criterios preventivos de riesgos producidos por la conducción de automóviles, los que pueden tener su origen en el propio vehículo motorizado, en la capacidad e idoneidad del conductor o en la confluencia de múltiples conductores en las vías públicas.

En virtud de lo anterior, y del especial tratamiento asignado a la licencia de conducir como acto administrativo habilitante para circular en vehículos motorizados, actividad per se riesgosa para terceros, es que justifican la imposición de una nueva sanción por acumulación de infracciones graves o gravísimas al tránsito.

8. En este mismo sentido, sentencia del Tribunal Constitucional, rol 1888-10, 2010, voto por rechazar requerimiento, considerando decimoquinto. 


\section{Fundamentos y razones para concluir que no existió en la especie una vulneración al principio non bis in idem}

Respecto de este punto, señalan los ministros que la garantía penal del non bis in idem implica una restricción de carácter procesal y una de carácter material o sustantiva establecida para el juez sentenciador. En efecto, reiteran en los diversos fallos sobre la materia que la prohibición del non bis in idem tiene como destinatario de referencia normativa fundamental al sentenciador que, en un caso concreto, debe resolver si es que un hecho sometido a un procedimiento radicado en su competencia ya ha sido juzgado, siguiendo la clásica regla de coincidencia de sujetos, hechos y fundamentos, o si el comportamiento que ha de ser juzgado se describe y sanciona en diversas disposiciones sin fundamento para ello, lo que se denomina prohibición de doble valoración. En otras palabras, el non bis in idem no prohíbe que un mismo infractor pueda ser objeto de dos sanciones por un mismo hecho, siempre que la imposición de una y otra sanción respondan a un fundamento jurídico diverso.

Para estos sentenciadores, las dos sanciones impuestas in actum por la comisión de las infracciones primitivas no comparten el mismo fundamento ontológico que la tercera sanción a imponerse por acumulación de infracciones, atendida la diferencia en la configuración de los hechos normativos sancionables, y en cuanto a los bienes jurídicos tutelados. En este sentido, la argumentación se basa en que en el tercer proceso jurisdiccional, por acumulación de infracciones previas, no se examinarán nuevamente los hechos ya juzgados y sentenciados preliminarmente, sino que consistirá en un procedimiento nuevo que permita aplicar una sanción efectiva a quien incurra en la especial conducta de infringir reiteradamente las normas del tránsito en un periodo determinado, con lo que, al parecer, también darían por solucionados los problemas de tipicidad en la descripción de la conducta, identificados por la postura contraria.

A mayor abundamiento, señalan que

El legislador no estableció una sanción sin una conducta previa valorada negativamente, ya que la norma que contiene la sanción y el procedimiento para su tramitación se basa en una hipótesis punible nueva, distinta a una infracción individualmente analizada, pues se trata de dos infracciones en un tiempo determinado. La finalidad de la norma es regular, con anterioridad a la perpetración del hecho, la hipótesis de varias infracciones cometidas un mismo conductor, como manifestación de una vulneración sistemática a las reglas del tránsito, en función a los bienes jurídicos que protege, lo que resulta distinto a un conductor infractor ocasional (sentencia del Tribunal Constitucional, rol 3000-16, 2016, voto disidente por rechazar, considerando vigésimo octavo). ${ }^{9}$

Esta postura considera que un conductor que incurre en dos infracciones graves o gravísimas a la Ley de Tránsito en un periodo de doce meses es un conductor contumaz y temerario, el que con su conducta al volante pone en riesgo un bien jurídico com-

9. En este mismo sentido, sentencia del Tribunal Constitucional, rol 2402-13, 2013, voto de mayoría por rechazar el requerimiento, considerando trigésimo quinto. 
plejo, integrado por la seguridad vial y del tránsito, como bien jurídico intermedio o instrumental, y la vida e integridad física y síquica como bien jurídico mediato o final.

Por tanto, el bien jurídico protegido en las infracciones originalmente sancionadas es la seguridad vial como interés colectivo, mientras que el bien jurídico cautelado por la sanción por acumulación de infracciones es un bien jurídico complejo que involucra, además de la seguridad en las vías públicas, la debida protección de la vida e integridad física y síquica de terceros.

En conclusión, los sentenciadores consideran que una actitud de contravención reiterada a la reglas del tránsito es mirada negativamente por el legislador, ya que la pluralidad de infracciones se orienta hacia un disvalor diferente de aquel que comete un infractor de tránsito común y ocasional, imponiéndose una nueva sanción especial al infractor contumaz si la reincidencia se produce en un tiempo determinado, por lo que dicha decisión legislativa no vulneraría el non bis in idem, ya que el fundamento de la sanción y la naturaleza del procedimiento para su imposición son distintos a los fundamentos y naturaleza provenientes de las contravenciones originales que lo causan, compartiendo con aquéllos solo la identidad subjetiva o de hechor, mas no identidad en la configuración normativa de los hechos ni en su fundamento jurídico.

\section{Comentarios y propuestas del autor respecto a la aplicación del artículo 207 letra b) de la Ley de Tránsito y en específico su relación con el principio non bis in idem}

Conforme se adelantó, tradicionalmente el principio non bis in idem puede ser analizado desde dos perspectivas: una de carácter sustantivo o material, que prohíbe imponer a un sujeto un doble castigo por un mismo hecho y cuyo fundamento es la "prohibición de punición múltiple»; y otra de orden procesal, a través de la cual se prohíbe someter a un sujeto más de un proceso por los mismo hechos y fundamentos tras una decisión judicial firme, sea o no condenatoria, en el que éste es el efecto negativo de la cosa juzgada: la "prohibición de juzgamiento o persecución múltiple» (Gómez González, 2017: 104).

Por tanto, resulta contrario a toda lógica y certeza jurídica que si un asunto ya fue investigado y discutido a nivel judicial o administrativo, ajustándose a cada una de las etapas procesales contempladas en la ley, sea nuevamente abierto, con lo que mantiene al particular en una incertidumbre intolerable en un Estado de derecho, ya que el ius puniendi estatal debe ser ejercido en un solo momento, de la manera y con la intensidad prevista por el legislador, y deben imponerse en dicha oportunidad todas las medidas sancionatorias procedentes ya sean principales o accesorias, por lo que fuera de dicho momento se agota la posibilidad de aplicarlas.

Cabe mencionar que en los casos concretos de inaplicabilidad por inconstitucionalidad de la sanción por acumulación de infracciones graves o gravísimas al tránsito no nos encontramos frente a la clásica discusión en el derecho administrativo sancionador en materia de non bis in idem, consistente en que si una misma conducta satisface simultáneamente un tipo penal y un tipo administrativo, se debe definir cuál 
de las dos sanciones debiese privilegiarse en su aplicación, si la vía penal o la vía administrativa, de manera de no vulnerar la prohibición de doble sanción por un mismo hecho. Diversa es la situación cuya constitucionalidad se cuestiona en la especie, ya que ésta consiste en que producto de unos mismos hechos fiscalizados y denunciados por la Administración, ${ }^{10}$ concurran en contra del responsable dos o más sanciones de carácter infraccional-contravencional impuestas por un tribunal especial que ejerce jurisdicción, pero que no forma parte de los tribunales ordinarios que integran el Poder Judicial, como son los Juzgados de Policía Local. En palabras del profesor Mañalich, reafirmando la operatividad del principio non bis in idem, cuando se trata de la imposición por un mismo hecho de dos o más sanciones administrativas o contravencionales, como en el caso en análisis, sostiene que

cabe ocuparse primero del alcance de la prohibición de punición múltiple frente a la posible imposición acumulativa de sanciones penales y sanciones administrativas, para después determinar el alcance de la prohibición de juzgamiento múltiple frente al eventual desarrollo de investigaciones o procesos eventualmente conducentes a la imposición de sanciones de una y otra índole. Pero antes de entrar en ello, puede ser conveniente introducir una prevención: lo que aquí está en juego no es si acaso el principio ne bis in idem resulta operativo como estándar sustantivo y como estándar procesal al interior de los regímenes del derecho administrativo sancionatorio, esto es, en lo que cabría llamar frente intracompetencial. Pues ello es algo que puede darse por sentado si se valida su caracterización como una estándar general de derecho sancionatorio. Lo que está en juego es si en qué medida el principio ne bis in idem resulta operativo frente al potencial entrecruzamiento de regímenes de derecho penal y derecho administrativo sancionatorio, esto es lo que cabría llamar frente intercompetencial (Mañalich, 2014: 558).

Resulta evidente para este autor que la garantía del non bis in idem resulta plenamente operativa en el régimen sancionatorio-administrativo relativo al tráfico y conducción de vehículos motorizados, y consecuentemente a la sanción por acumulación de infracciones.

Pues bien, los argumentos sobre los cuales sostendré que la aplicación de la referida norma sí vulnera el non bis in idem son de dos tipos: los primeros de carácter sustancial o de fondo, y los segundos de carácter procedimental o de forma.

10. En la generalidad de las infracciones al tránsito, la facultad de fiscalizar y denunciar es entregada por ley a funcionarios de Carabineros de Chile, fiscalizadores del Ministerio de Transporte y Telecomunicaciones e inspectores municipales. En el caso de los procesos por acumulación de infracciones graves o gravísimas al tránsito, la legitimidad para denunciar e iniciar un proceso sancionatorio en contra del infractor recae únicamente en el Servicio de Registro Civil e Identificación; luego, la determinación y aplicación de la sanción por acumulación de infracciones recaerá imperativamente sobre el Juzgado de Policía Local competente. 


\section{Aspectos materiales y sustanciales}

A diferencia de lo sostenido en los fallos que rechazaron algunos de los requerimientos incoados, considero que, entre las infracciones graves o gravísimas al tránsito originales cometidas en los últimos doce meses y sus respectivas sanciones, y la sanción por incurrir en acumulación de infracciones graves o gravísimas a la Ley de Tránsito, sí concurren los requisitos de la triple identidad de sujetos, objeto y fundamento, para que opere la prohibición de doble sanción por un mismo hecho.

El bien jurídico protegido en todas las infracciones o contravenciones previstas en la Ley de Tránsito consiste en la seguridad vial y en el tráfico de vehículos motorizados, concebido como un interés general y colectivo de la sociedad, pero que no se extiende más allá de este único objeto, por lo que al intentar extender su ámbito de protección y considerar otros intereses como bienes jurídicos protegidos por esta clase de normas de la legislación de tránsito, tal como el derecho a la vida e integridad física y síquica, implicaría incurrir en un error, ya que si bien se comparte la opinión de que la conducción de vehículos motorizados genera riesgos mayores que otro tipo de actividades, éstos ya se encuentran cubiertos por un abundante listado de conductas infraccionales relacionadas con el tráfico vehicular, no constitutivas de delito, y cuya comisión se encuentra prohibida y sancionada. Asimismo, la seguridad en el tráfico como bien jurídico encuentra protección y resguardo a través de la existencia de condicionantes o restricciones, tanto para los vehículos motorizados como para los conductores, lo que, como se expondrá, solo tiene por finalidad asegurar el correcto funcionamiento de las vías públicas y la seguridad en el tráfico vehicular.

Pues bien, esta identidad de fundamento y de bienes jurídicos entre normas y procedimientos se propugna solo respecto de aquellas infracciones o contravenciones a la Ley de Tránsito que no revisten un carácter delictual. Además, el título 17 numeral 2 de la Ley de Tránsito 18.290 contiene aquellas infracciones y contravenciones a las reglas del tránsito y que son conductas que vulneran estas disposiciones, pero que no revisten el carácter de delitos. Los tipos penales relacionados con la conducción de vehículos motorizados se encuentran previstos tanto en el título 17 numeral 1 de la Ley de Tránsito, como en el título 10 del libro tercero del Código Penal, cuerpos normativos donde no existe duda en que se consagran figuras delictuales como el manejo en estado de ebriedad con resultado de daños, de lesiones e incluso de muerte; o bien, el cuasidelito de homicidio, lesiones graves o gravísimas causadas mediante la conducción de vehículos motorizados, todo tipos penales respecto de los cuales sí puede afirmarse que pretenden alcanzar una finalidad ulterior, más allá del correcto funcionamiento del tráfico vehicular, como la protección de la vida, la salud y la integridad física, entre otros bienes jurídicos relevantes. ${ }^{11}$

11. Un ejemplo de la relevancia que reviste para el legislador la protección de este tipo de bienes jurídicos ulteriores, como la vida y la integridad física y síquica, es la dictación de la Ley 20.580, que «Modifica la Ley de Tránsito en lo relativo al aumentos de sanciones por manejo en estado de ebriedad y sustancias 
El profesor García Cavero señala, respecto de la distinción entre infracciones y sanciones penales y administrativas-contravencionales, que

la sanción administrativa se sustenta en algo cualitativamente distinto a la pena. Administrativamente lo que la sanción administrativa procura es generar las condiciones empíricas para que el sector social regulado no colapse. Lo usual es conseguirlo por medio de estímulos negativos externos sobre los administrados que los motiven a observar los estándares de actuación establecidos. [...] La situación es sustancialmente distinta en el caso de la pena. Esta sanción se dirige al condenado como ser racional para negar comunicativamente el sentido social de su actuación delictiva, lo que hace imprescindible la realización de un juicio de culpabilidad por un hecho propio (García Cavero, 2016: 28).

Pues bien, el presente trabajo se refiere a aquellos tipos infraccionales-contravencionales y no tipos penales, y que se dividen en un largo listado de conductas prohibitivas dependiendo de la gravedad asignada por el legislador a cada una de ellas.

El artículo 199 de la Ley de Transito contiene las denominadas infracciones gravísimas, entre las que se consideran el no detenerse ante una señalética de disco pare o luz roja, así como conducir un vehículo motorizado sin haber obtenido licencia de conducir, entre otras.

A su vez, el artículo 200 del mismo cuerpo legal contiene un extenso listado con las infracciones graves, como conducir un vehículo motorizado en determinadas hipótesis: sin tener puesto cinturón de seguridad, hablando por celular, sin revisión técnica, con las luces apagadas, con neumáticos en mal estado, con restricción vehicular o hacer un viraje en sitio prohibido y señalizado, entre otras.

El artículo 201, a su vez, contiene un listado con las infracciones menos graves, entre las que se cuenta el conducir un vehículo motorizado sin portar chaleco reflectante, sin extintor o con vidrios polarizados.

El artículo 202, por su parte, contiene las infracciones de carácter leve; consiste en una figura residual para incluir a todas aquellas infracciones no previstas en los numerales anteriores.

Por último, el artículo 203 de la Ley de Tránsito consagra de manera independiente la infracción de conducir un vehículo motorizado a exceso de velocidad, estableciendo su gravedad de acuerdo con los kilómetros o velocidad en exceso a la que fuere sor-

sicotrópicas, o bajo la influencia del alcohol», publicada el 15 de marzo de 2012 y conocida coloquialmente como «ley Emilia». Lo anterior pretende lograr que con este aumento en la punición estatal de este tipo de conductas delictuales se protejan de mejor manera la vida, la integridad física y síquica y el derecho de propiedad de las personas, conductores, ciclistas y peatones, toda vez que ingerir alcohol o drogas antes o durante la conducción de vehículos motorizados efectivamente disminuye la capacidad y habilidades de reacción de todo conductor, por lo que su comisión dará cuenta de lo temerario y contumaz de su conducta y estimándose que no existe tal evidencia de contumacia y despreocupación por bienes jurídicos ajenos en aquellos conductores que incurran en una acumulación de infracciones graves o gravísimas a la Ley de Tránsito. 
prendido conduciendo el infractor, a saber: si excedió el límite máximo en $10 \mathrm{~km} / \mathrm{h}$, se considerará infracción menos grave; si lo superó por más de $11 \mathrm{~km} / \mathrm{h}$ y menos de 20 $\mathrm{km} / \mathrm{h}$ se considera infracción grave; y por último, si superó con su conducción el límite máximo en más de $20 \mathrm{~km} / \mathrm{h}$, se considerará una infracción gravísima. ${ }^{12}$

En conclusión, las normas y procesos concurrentes en la acumulación de infracciones protegen el mismo bien jurídico y comparten un fundamento homogéneo, por lo que no procedería una doble punición a pesar de que los artículos vulnerados de la Ley de Tránsito sean diversos.

Otro punto que considerar, a propósito de la inconstitucionalidad en la aplicación del artículo 207 b) de la Ley de Tránsito, dice relación con lo previsto en el artículo 204 inciso tercero del mismo cuerpo legal, el que, luego de valorizar las multas procedentes por cada tipo de infracción, señala:

A los reincidentes de infracciones gravísimas o graves, cometidas en los últimos tres y dos años, respectivamente, se les impondrá el doble de la multa establecida para cada infracción, la que se elevará al triple en caso de incurrirse nuevamente en dicha conducta. Lo anterior, sin perjuicio de las suspensiones o cancelaciones de licencias de conductor que corresponda (artículo 207, letra b).

Es decir, con la norma recién transcrita, el legislador ya ponderó y le asignó un mayor reproche o disvalor a la reincidencia, incluso considerando un plazo mayor a los doce meses previstos en el artículo 207 letras b), y que le permite al juez, en la hipótesis de reincidencia de una infracción al tránsito grave o gravísima, cometida dentro de los últimos dos o tres años respectivamente, considerar la primera infracción para efectos de aumentar al doble e incluso al triple la multa por la comisión de una segunda, lo cual no obsta a las suspensiones o cancelaciones de licencia de conducir que correspondan. Por tanto, con esta disposición ya se encontraría cubierta la supuesta finalidad preventiva y disuasoria que algunos creen ver en la sanción por acumulación de infracciones, lo que evidencia un incorrecto despliegue de los objetivos de política punitiva estatal, y por tanto un intento del legislador de extender más allá de lo necesario un régimen sancionatorio adicional a los ya contemplados en la propia normativa, lo cual soslaya el hecho de que cualquier ajuste en la reacción punitiva estatal no puede configurarse, desde el punto de vista constitucional, de manera arbitraria.

La norma legal impugnada en los diversos requerimientos da lugar a una doble valoración de la reincidencia, y lo hace, por cierto, de una manera excesiva, al imponer adicionalmente y sin una nueva conducta una sanción de magnitud incrementada, lo que produce en la práctica una superposición de efectos punitivos.

Además, el mismo artículo 204 inciso sexto regula de forma expresa un caso de concurso ideal de infracciones al tránsito, lo que, a su vez, incide justamente en la

12. Con fecha 4 de agosto de 2018 se publicó en el Diario Oficial la Ley $\mathrm{N}^{\circ} \mathbf{2 1 . 1 0 3}$, que modificó la Ley de Tránsito, en lo relativo a la velocidad máxima de circulación en zonas urbanas, reduciendo su límite máximo de $60 \mathrm{~km} / \mathrm{hr}$ a $50 \mathrm{~km} / \mathrm{hr}$. 
aplicación del principio non bis in idem, optando el legislador por sancionar en un solo momento y por una única vez con la sanción de multa correspondiente a la infracción de mayor grado, por lo que nuevamente se evidencia un exceso punitivo por parte del legislador, ya que con lo previsto en las disposiciones mencionadas ya se encontrarían cubiertos todos los riesgos que supuestamente se pretendieron evitar con el establecimiento de la sanción por acumulación de infracciones al tránsito.

Concluye la jurisprudencia administrativa de la Contraloría General de la República, en este mismo sentido, que en aquellos casos en los cuales la ley ha previsto más de una sanción para una determinada infracción, aquello será admisible cuando proceda y de manera excepcional, respecto de las infracciones más graves que contemple la respectiva regulación; puesto que, de lo contrario, se afectaría el principio del non bis in idem que limita el ejercicio de las potestades sancionatorias de la Administración, las que se deben ejercer sin arbitrariedad, llegando a decisiones racionales, justas y equitativas, desprovistas de discriminación y proporcionales a las falta y mérito del proceso (Dictamen de la Contraloría General de la República 4.197 de 2008).

Otra situación a considerar en la especie dice relación con un aspecto subjetivo y práctico que recae sobre los conductores de vehículos motorizados, en el sentido de que la licencia de conducir resulta ser una herramienta fundamental para gran parte de los ciudadanos en el cumplimiento de sus obligaciones laborales, familiares, de salud, entre otras; por ello es que en la mayoría de los procesos sancionatorios por infracciones a la Ley de Tránsito lo que en especial complica a los conductores-infractores es precisamente la sanción de suspensión de su licencia de conducir.

De conformidad con lo anterior, podría ocurrir una situación en que, según mandata el artículo 216 de la Ley de Tránsito, se inicie por parte del Servicio de Registro Civil e Identificación un proceso por acumulación de infracciones en que un conductor habitual, el que por lo general es respetuoso de las reglas del tránsito, y que además utiliza a diario su licencia de conducir para desplazarse, razón por la que se encuentra mayormente expuesto a ser fiscalizado e infraccionado por cualquiera de las conductas previstas en los artículos 199 y 200 de la Ley de Tránsito, algunas de las cuales son precisamente las infracciones graves, de muy común ocurrencia en los caminos públicos y que en caso de producirse no implica necesariamente que el conductor que incurrió en ellas dentro de los últimos doce meses tenga que inmediatamente ser considerado un conductor temerario y contumaz, y que ello que amerite imperiosamente una sanción de suspensión o cancelación de su licencia de conducir. ${ }^{13}$

13. Al respecto, surge como cuestionamiento la hipótesis de que, por la aplicación irrestricta del artículo en cuestión, pudiese resultar calificado de contumaz o peligroso para terceros un conductor que sea fiscalizado e infraccionado en dos oportunidades sucesivas dentro de los últimos doce meses por infracciones graves, como efectuar una maniobra de viraje ancho, circular con el certificado de emisión de gases vencido, conducir a una velocidad menor a la mínima permitida, no respetar la preferencia en un paso peatonal, conducir un vehículo con restricción vehicular o cualquier otra infracción grave del listado del artículo 200 de la Ley de Tránsito, que no diga relación estrictamente con actitudes temerarias o contumaces incurridas por el conductor, sino que atribuibles a la propia dinámica de la conducción de vehículos 


\section{Aspectos procedimentales de la sanción por acumulación de infracciones}

Conforme se ha explicado, el principio non bis in idem, en su vertiente procedimental, implica una prohibición de llevar adelante procesamientos sancionatorios múltiples, sea en uno o más órdenes jurídicos punitivos, por el o los hechos, por los sujetos y por los fundamentos sobre los cuales haya recaído una sentencia firme condenatoria o absolutoria, una decisión de cesación de los procedimientos o bien una resolución de preclusión de la investigación (Gómez González, 2017: 117).

En otras palabras, el Estado tiene una oportunidad para perseguir y castigar al sujeto infractor $y$, una vez ejercida, no podrá reiterarse nuevamente, aun cuando se invoquen nuevos antecedentes o calificaciones jurídicas. Por tanto, se prohíbe la tramitación de varios procedimientos sancionatorios sucesivos por unos mismos hechos, sea que los primeros hayan concluido o no con responsabilidad del autor, lo que conllevaría a una reiteración desproporcionada en el ejercicio del ius puniendi estatal y que afecta la certeza y seguridad jurídica, atendido a que el órgano jurisdiccional ya tuvo su oportunidad de perseguir las responsabilidades contravencionales derivadas de la infracción. ${ }^{14}$

En cuanto al procedimiento establecido para la aplicación de la sanción por acumulación de infracciones, el artículo 40 de la Ley 18.287, sobre Procedimientos ante los Juzgados de Policía Local, regula ciertos aspectos de dudosa constitucionalidad, cuya tramitación no resguarda correctamente las garantías previstas en el artículo 19 numeral 3 de la Constitución, como el debido proceso, la bilateralidad de la audiencia, la posibilidad de aportar prueba y la impugnabilidad de las resoluciones judiciales, entre otras.

Reza el referido artículo:

El juez, con la información que le envíe el Registro Nacional de Conductores, citará al afectado a una audiencia para un día y hora determinados, en la que deberán hacerse valer los descargos.

Para tal efecto, se citará al conductor afectado mediante cédula, en extracto, que se

motorizados en las carreteras públicas, no obstante lo cual este conductor será nuevamente sancionado con una suspensión de licencia, a pesar de haber pagado la primera multa, y de haber cumplido con la segunda multa y suspensión, según lo dispone el artículo 207 letra b), lo que se traduce finalmente en un prejuzgamiento desproporcionado por parte del legislador, que no tiene en consideración las circunstancias personales, especificas o de contexto del infractor al momento de aplicarse la tercera sanción.

14. En este sentido, la Corte de Apelaciones de Santiago señaló que «no resulta procedente iniciar una nueva investigación administrativa sobre los mismos hechos por otro organismo fiscalizador, como en este caso lo es la Superintendencia de Valores y Seguros, aunque éste sea competente para vigilar el cumplimiento de las normas sobre uso de información privilegiada contenidas en la Ley 18.045 y esté, eventualmente, dotado de mayores facultades que le permitirían reunir una mejor prueba para acreditar la infracción que no pudo establecer el otro organismo fiscalizador, toda vez que ello implicaría efectuar una doble persecución por parte del Estado respecto de unos mismos hechos, lo que atenta contra el principio del non bis in idem y conlleva el riesgo de tener que enfrentar decisiones contradictorias». Sentencia de Fernando Mondaca Melet con Superintendencia de Valores y Seguros, Corte de Apelaciones de Santiago, rol 9729-2002, 31 de marzo de 2008, considerando decimocuarto. 
dejará en su domicilio. Si no concurriere a la citación o el domicilio registrado no le correspondiere o fuere inexistente, el juez ordenará su arresto para que concurra a la presencia judicial.

Efectuados los descargos, el juez fallará en el acto o recibirá la prueba, decretando todas las diligencias que estime pertinentes.

No procederá recurso alguno contra las sentencias y demás resoluciones que se dicten en este procedimiento (Ley 18.287, artículo 40).

En relación con el procedimiento de acumulación de infracciones, la legitimidad activa para iniciar dicho procedimiento recae sobre un órgano de carácter administrativo, como es el Servicio de Registro Civil e Identificación, el que, en virtud del artículo 216 de la Ley de Tránsito, remitirá al juez del domicilio del infractor una denuncia por acumulación de infracciones. Luego de ello, el juez ordenará citar a audiencia al infractor y, en caso de no concurrir, ordenará su arresto.

Lo anterior resulta absolutamente arbitrario y contrario a la seguridad individual y libertad ambulatoria del infractor, toda vez que este derecho podría verse gravemente conculcado producto de una denuncia iniciada por un órgano de carácter administrativo, por una supuesta infracción que no reviste una correcta descripción de la conducta contravencional y que da origen a una citación judicial que, en caso de no comparecencia, permite el arresto del infractor citado. ${ }^{15}$

Luego, y al no existir una conducta sancionable previamente descrita por ley, ni menos una formulación legal de cargos respecto de los cuales poder defenderse, se ve violentado además el derecho a la defensa judicial y la posibilidad de desvirtuar las imputaciones mediante la aportación de pruebas. En este sentido, y correctamente según parecer de este autor, los ministros que sostienen la inconstitucionalidad en la aplicación del artículo 207 letra b) de la Ley de Tránsito coinciden en que la citación judicial deviene en un simple aviso respecto de la puesta en marcha de un proceso inexorable, predestinado a obtener su sola e ineludible inculpación de haber saldado y cumplido aquellas preexistentes penas que, a su vez, conducen en forma irremisible a la imposición de una nueva condena de suspensión o cancelación de licencia.

Por tanto, el legislador, en un intento por lograr mayores índices de eficacia coercitiva, restringe la labor jurisdiccional a una función meramente maquinal de hacer ejecutar una pena que viene pre-impuesta desde fuera de los estrados, cercenando su premisa básica consistente en conocer y juzgar del asunto sometido a su conocimiento.

Por último, otro aspecto negativo previsto en el procedimiento para la aplicación de la sanción por acumulación de infracciones dice relación con lo señalado en el inciso final del artículo 40 de la Ley 18.287 , en cuanto establece la inimpugnabilidad de las resoluciones dictadas en el procedimiento por acumulación de infracciones; es decir, no proceden ulteriores recursos en contra de la mecánica y poco sopesada decisión

15. Sobre la proscripción de que un órgano administrativo pueda dictar actos administrativos sancionatorios restrictivos de la libertad personal, véanse las sentencias del Tribunal Constitucional, roles 244-96, 479-06, 480-06 y 1518-09, de 1996, 2006 y 2009 respectivamente. 
judicial de suspender o cancelar la licencia de conducir. Por tanto, se estima que esta norma violenta directamente el derecho a un debido proceso, consagrado en el artículo 19 numeral 3 de la Constitución, toda vez que la posibilidad de provocar una revisión de lo fallado por una instancia superior es parte inherente de un justo y racional procedimiento.

Entonces, ya analizados los problemas de constitucionalidad que genera la aplicación de del artículo 207 letra b) de la Ley de Tránsito tanto a nivel sustantivo como adjetivo, es posible concluir que su aplicación a un caso concreto vulnera abiertamente el principio del non bis in idem, además de las otras garantías anteriormente desarrolladas, ya que resulta ilógico que se someta indefinidamente a un sujeto a persecuciones sancionatorias cuando éste ya ha sido juzgado, absuelto o condenado y ha cumplido su condena. La existencia de múltiples procedimientos sancionatorios, penales o administrativos, sin importar su orden temporal, afecta los cimientos de este principio, menoscabando la confianza legítima depositada por los ciudadanos en el sistema jurídico-sancionatorio.

La profesora española Belén Marina Jalvo concluye al efecto que

Existe una prohibición constitucional, dirigida al Estado, de someter a los ciudadanos a un doble o ulterior procedimiento sancionador por los mismos hechos y con el mismo fundamento. Esta prohibición actúa como un límite al ejercicio de la potestad sancionadora y deriva del derecho a ser sancionado en un procedimiento con todas las garantías, en relación con la garantía de la seguridad jurídica y la libertad (Marina Jalvo, 2003, 183).

Finalmente, un correcto diseño legislativo sancionatorio es aquél que prevé garantías para el infractor, como que las sanciones sean impuestas en un único momento, ya sea por un tribunal o un órgano de la administración, de manera de que el infractor enfrente en una sola instancia la proyección del poder punitivo estatal, teniendo la posibilidad cierta de desplegar sus mecanismos de defensa y de prueba, tendientes a desvirtuar las acusaciones y, en caso de ser sancionado, cumplir en esa misma oportunidad las sanciones impuestas, lo que por cierto resulta conveniente para los intereses del Estado punitivo, en orden a la eficiencia, eficacia y gestión de recursos públicos.

\section{Algunos comentarios respecto de las normas que regulan la obtención o renovación de la licencia de conducir y su posible afectación al principio non bis in idem}

Existe otro grupo de disposiciones en la Ley de Tránsito en los que, a entender de quien expone, presentan serios reparos de constitucionalidad, específicamente en lo que dice relación con los requisitos para la obtención de la licencia de conducir y su afectación a la prohibición de ser sancionado dos veces por un mismo hecho.

Al efecto, el artículo 13 del referido texto legal establece, dentro de los requisitos para la obtención o renovación de la licencia de conducir, la obligación de acreditar la 
«idoneidad moral» por parte del solicitante. A su vez, según lo dispone el artículo 14 letras a) y b) del mismo cuerpo legal, la idoneidad moral del solicitante será calificada por el director del Departamento de Tránsito y Transporte Público Municipal respectivo, a la vista del informe de antecedentes expedido por el Servicio de Registro Civil e Identificación y del informe del Registro Nacional de Conductores, cuya fecha de emisión no sea anterior a 30 días y en el que se contengan todas las anotaciones que se registren, constando en él que el solicitante no se encuentre afecto a pena de suspensión o de inhabilidad para conducir vehículos, ni que se le ha denegado con anterioridad al postulante la licencia que hubiere solicitado.

En seguida, el artículo 16 agrega que, para calificar la idoneidad moral de los interesados, se considerarán las condenas que haya sufrido en los cinco años anteriores, por las siguientes causas:

- Por delitos, cuasidelitos, faltas, infracciones o contravenciones a la presente ley, a la Ley sobre Expendio y Consumo de Bebidas Alcohólicas y a la Ley 20.000, sobre Tráfico Ilícito de Estupefacientes y Sustancias Sicotrópicas;

- por delitos o cuasidelitos para cuya perpetración se hubiere utilizado un vehículo;

- por delitos contra el orden de la familia y la moralidad pública; y

- por el delito de conducir con licencia de conductor, boleta de citación o permiso provisorio judicial para conducir, falsos u obtenidos en contravención a esta ley o pertenecientes a otra persona.

Finalmente, el artículo 15 inciso tercero de la Ley de Tránsito señala que el postulante afectado por un rechazo en su solicitud de obtención o renovación de licencia de conducir por falta de idoneidad moral podrá reclamar, dentro de los cinco días hábiles siguientes de notificada esta resolución, ante el juez de Policía Local respectivo, el cual resolverá breve y sumariamente y apreciará la prueba en conciencia, no procediendo en contra de su resolución recurso alguno.

En resumen, el legislador dispuso que para el trámite de obtención o renovación de licencia de conducir se deben considerar las condenas firmes y ejecutoriadas que registre el solicitante dentro de los últimos cinco años, a pesar de que por aquellos hechos ya haya sido objeto de una investigación penal que derivó en la imposición de una sanción principal o accesoria y, habiendo cumplido con ellas, se considerarán nuevamente los mismos hechos investigados y sancionados como un impedimento para la obtención o renovación de su licencia de conducir, la que conforme se explicó, implica una herramienta fundamental para la vida de muchos conductores habituales de vehículos motorizados o de personas que buscan reintegrarse en la sociedad, luego de haber cumplido con una condena por la comisión de alguno de los delitos ya señalados.

Resulta completamente desproporcionado y ajeno a toda lógica razonable de política criminal el hecho de aplicar una nueva sanción, principalmente respecto de delitos que nada tienen que ver con la conducción de vehículos motorizados y los riesgos 
que ella involucra, por lo que no se comprenden las razones para el diseño legislativo preventivo y punitivo establecido por el legislador, principalmente en aquellas disposiciones previstas en los numerales 1 y 3 del artículo 16 de la Ley de Tránsito, como delitos, cuasidelitos, infracciones, o faltas a la ley sobre expendio y consumo de bebidas alcohólicas o a la Ley 20.000 sobre tráfico ilícito de estupefacientes y sustancias sicotrópicas, o bien, delitos contra el orden de la familia y la moralidad pública, por lo que existe un nuevo caso de exceso punitivo estatal por parte del legislador, dentro de las disposiciones establecidas en la Ley 18.290.

El conjunto de disposiciones anteriormente señaladas presenta serios cuestionamientos respecto de su constitucionalidad, en relación con la garantía del non bis in idem frente a las sanciones o medidas dispuestas por la autoridad estatal.

En primer lugar, no parece adecuado que un hecho respecto del que ya existió un pronunciamiento judicial firme y que fue cumplido, vuelva a ser tomado en consideración por una autoridad de carácter administrativo, otorgándose la facultad discrecional a los directores de tránsito de las municipalidades para calificar la idoneidad moral de los solicitantes, ya que en caso de denegarse dicha solicitud de postulación o renovación por carecer de este requisito la decisión implicaría una nueva y verdadera sanción en contra de un sujeto, el que ya fue objeto de un reproche punitivo estatal, en razón de un delito o cuasidelito que originó la respectiva anotación en su hoja de vida de conductor o extracto de filiación.

Lo anterior violenta directamente el principio jurídico del non bis in idem, en virtud del cual nadie puede ser sancionado dos veces por el mismo hecho, más aún si quien impone y determina la segunda pena es una autoridad administrativa, y cuyo marco normativo para calificar la idoneidad moral quedará entregado, según el artículo 15 inciso primero de la Ley de Tránsito, al Ministerio de Transporte y Telecomunicaciones, mediante el uso de su potestad reglamentaria (Instituto Libertad y Desarrollo, 2000).

En este sentido, la Corte de Apelaciones de Valparaíso determinó, en un recurso de protección interpuesto por un infractor al cual se le denegó la renovación de su licencia de conducir, que el acto recurrido constituía la imposición de una doble sanción por el mismo hecho, lo que configura un vicio de desviación de poder y una ilegalidad incurrida por la autoridad administrativa. ${ }^{16}$

En segundo lugar, y como cuestionamiento de carácter adjetivo o procedimental, y en términos similares a lo expuesto a propósito del procedimiento de acumulación de

16. Sentencia del caso Rafael Lüttges Derosas con directora del Departamento de Tránsito de la I. Municipalidad de La Calera señora Nora Gutiérrez Núñez, Corte de Apelaciones de Valparaíso, rol ProtecciónAnt-54-2006, de 27 de abril de 2006. En efecto, en los considerandos segundo y tercero se concluye por los ministros que, de acuerdo con lo expuesto, ha quedado en evidencia que al recurrente, en el hecho, se le está imponiendo una doble sanción: una por la infracción cometida en el año 2004, la que se encontraría cumplida, y otra, la reclamada, al disminuírsele el periodo de extensión de su licencia, lo que resulta arbitrario; y que la autoridad recurrida, al hacer aplicable las situaciones contempladas en el artículo 18 de la Ley de Tránsito al caso, ha incurrido en una verdadera desviación de poder, por lo que su actuar, además de arbitrario, es ilegal. 
infracciones, en el caso de denegación en la obtención o renovación de licencia de conducir se establece un procedimiento de revisión de la determinación administrativa, ante el Juzgado de Policía Local respectivo, órgano que apreciará los antecedentes en conciencia para resolver y respecto del cual, en contra de su determinación, no procederá recurso alguno, estableciéndose nuevamente un caso de impugnabilidad de una resolución judicial que se pronunció respecto de una sanción surgida al considerarse un hecho ya penado con anterioridad.

Por tanto, se estima que aun cuando las normas de la Ley de Tránsito 18.290, que regulan las exigencias para el otorgamiento o renovación de una licencia de conducir, referidas en especial a requisitos de idoneidad moral, le otorgan atribuciones al director del Tránsito y Transporte Público para calificarla respecto del peticionario según los antecedentes que obren en su poder, ello no lo habilita para denegar el otorgamiento o renovación de la licencia de conducir, fundado únicamente en las anotaciones por condenas previas que se encuentren plenamente cumplidas, por lo que corresponderá efectuar una revisión crítica de la normativa vigente, bajo la óptica del non bis in idem y demás garantías mencionadas en el presente trabajo, ya que si las sanciones judiciales impuestas por la comisión de delitos se cumplieron inexorablemente, dicha conducta no podrá ser considerada para imponer una nueva y verdadera sanción de suspensión de licencia prevista en la normativa en cuestión. ${ }^{17}$

\section{Conclusiones}

Como razonamiento final, cabe preguntarse y discurrir si dentro de lo que el artículo 19 numeral 3 inciso quinto de la Constitución denomina como garantías de un proceso y una investigación racionales y justos, resulta legítimo, válido y acorde con dichas garantías frente al ius puniendi estatal, que una sentencia definitiva dictada por un Juzgado de Policía Local considere y aplique la sanción por acumulación de infracciones contenida en el artículo 207 b) de la Ley de Tránsito, no obstante que con ello se vulnere el principio del non bis in idem, junto con las demás garantías enunciadas en los apartados anteriores. Mismo análisis merece ser hecho en relación con el inciso sexto del artículo 19 numeral 3 de la Constitución, mandato que señala que la ley no podrá presumir de derecho la responsabilidad penal.

Pues bien, al parecer nada impide que si un juez de policía local pretende limitarse

17. Refuerza lo anterior un fallo reciente de la Corte de Apelaciones de Temuco, que sostuvo: «En tales circunstancias, en la presente situación se está imponiendo al peticionario una doble sanción por un hecho por el que ya fue castigado y en una hipótesis no prevista en la ley, con lo cual se está infringiendo el principio non bis in idem y la garantía constitucional del principio de legalidad. En efecto, la negativa de renovar la licencia de conducir al recurrente, en la práctica importa una cancelación de ésta por el hecho de conducir un vehículo motorizado en estado de ebriedad, en circunstancias que para que ello ocurra debe tratarse de una situación de reincidencia en los términos previstos en el artículo 196 letra e) de la Ley 18.290, lo cual no acontece en el presente caso» (sentencia de la Corte de Apelaciones de Temuco, rol 2936-2017, 2017, considerando quinto). 
a aplicar irrestrictamente la normativa vigente de la Ley de Tránsito e interpreta celosamente su tenor literal, pueda condenar a un infractor que se encuentre en alguno de los casos previstos en el artículo 207 letra b) de la Ley de Tránsito, de acuerdo con el procedimiento signado en la ley respectiva, no obstante que con su aplicación, bajo una óptica constitucional, pudiese vulnerar normas del debido proceso, y específicamente la prohibición de doble sanción por un mismo hecho.

Resulta por tanto indispensable estudiar y analizar, en casos como los descritos, si le asiste al infractor que ya cumplió con las sentencias condenatorias originales, por acumulación, alguna otra vía jurídica de defensa que no sea la recursiva jurisdiccional ante instancias superiores, dentro del nuevo proceso que se ha iniciado para sancionarlo por incurrir, dentro de los últimos doce meses, en una acumulación de infracciones graves o gravísimas al tránsito.

En apariencia, si el legislador discutió en todas las etapas y trámites constitucionales que prevé el proceso formativo de la ley, y decidió establecer una sanción por acumulación de infracciones, volviendo perseguibles y sancionables dichas conductas que per se constituyen una infracción ya sancionable, técnicamente dicha figura siguió de manera formal el cauce constitucional, lo que finalmente derivó en su publicación en el mes de marzo del año 1997, sin ser cuestionada, ni por la Contraloría General de la República ni por el Tribunal Constitucional, la constitucionalidad de dicho precepto, por lo que no cabría para el infractor ningún medio de impugnación ordinario ni extraordinario ante algún tribunal superior de justicia. ${ }^{18}$

Entonces, si las figuras punitivas comentadas, previstas en la Ley de Tránsito, no admiten medios de impugnación en sede judicial, resulta válido preguntarse cuál será la vía jurídica pertinente para obtener la derogación de estas normas que vulneran los principios y garantías ya desarrollados.

$\mathrm{Al}$ respecto, una posibilidad que le asistiría a un infractor que haya incurrido en la hipótesis en cuestión, y con la finalidad de que los mencionados artículos de la Ley de Tránsito resulten derogados, es la de recurrir primeramente al Tribunal Constitucional en sede de inaplicabilidad y obtener una sentencia que acoja dicho requerimiento, según lo previsto en el artículo 93 numeral 6 de la Constitución, para luego, una vez obtenida sentencia favorable, iniciar una acción de inconstitucionalidad por inaplicabilidad

18. A modo ilustrativo, cabe recordar un caso de ponderación y aplicación normativa similar y que consistió en aquellas causas con sentencias dictadas por los Juzgados de Policía Local, los que conociendo de infracciones en relación con el incumplimiento en el pago de la tarifa de autopistas concesionadas o comúnmente conocidas como multas «tag», las que según la redacción del antiguo artículo 42 del Decreto 900 que fija el texto refundido, coordinado y sistematizado de la Ley de Concesiones de Obras Públicas y que permitía al juez cobrar al infractor hasta cuarenta veces el valor de lo defraudado o no pagado por concepto de multas tag. Dichos fallos fueron invariablemente confirmados por la Corte Suprema, que declaró que la Ley de Concesiones de Obras Públicas, la que contemplaba dicha figura o conducta sancionatoria y por esos altísimos montos, por injusta que pareciera o fuera su aplicación, no adolecía de defectos formales o sustanciales que la hicieran inaplicable por los operadores jurídicos competentes, por vulnerar, por ejemplo, el principio de proporcionalidad de las sanciones. 
del artículo 207 letra b) en conjunto con el artículo 216, ambos de la Ley de Tránsito, de conformidad al artículo 93 numeral 7 de la Constitución. A su vez, el artículo 93 inciso decimosegundo de la Constitución señala al efecto que,

en el caso del numeral 7 , una vez resuelta en sentencia previa la declaración de inaplicabilidad de un precepto legal, conforme al número 6 de este artículo, habrá acción pública para requerir al Tribunal la declaración de inconstitucionalidad, sin perjuicio de la facultad de éste para declararla de oficio (Constitución Política de la República de Chile, 1980, artículo 93, inciso decimosegundo).

Por otro lado, a nivel de redacción legislativa de la norma se vislumbra otra posibilidad, tal vez menos demandante que la presentación de la acción constitucional enunciada anteriormente, y que consiste en una propuesta de modificación legal de los términos en que se encuentra redactado el encabezado del artículo 207 de la Ley de Tránsito, modificándose la palabra «decretará», redactada actualmente en términos imperativos, por una cláusula facultativa e interpretativa, que le permita mayor libertad al juez y se le otorgue mayor preponderancia al análisis y hermenéutica del operador jurídico por sobre una aplicación normativa irrestricta y poco sopesada. Señala en este sentido la profesora Ramírez Torrado:

Derivado de la finalidad del non bis in idem, se plantea la cuestión de a quién está dirigido éste: $\dot{\iota}^{a}$ la autoridad administrativa, que no puede sancionar en dos ocasiones al administrado, $o$ al legislativo, para que no cree infracciones que den lugar a la quiebra del principio? A lo que respondemos que está encaminado al operador jurídico, pues estos órganos son los que efectivamente imponen o no una sanción, o inician o no un nuevo procedimiento, ejercitando para ello, el ius puniendi, mientras que el legislador se limita a tipificar conductas sin hacer efectivo el poder sancionador de la Administración (Ramírez Torrado, 2013: 4).

Por ejemplo, una posible modificación en redacción del encabezado del artículo 207 de la Ley de Tránsito pudiese ser: «Sin perjuicio de las multas que sean procedentes, el juez podrá decretar la suspensión de la licencia de conducir del infractor, en los casos y por los plazos que se indican a continuación», o «sin perjuicio de las multas que sean procedentes, el juez ponderará el mérito y conveniencia de decretar la suspensión de la licencia de conducir del infractor, en los casos y por los plazos que se indican a continuación», lo que le otorga de esta manera mayores atribuciones interpretativas al juez, con el objeto de que analice las circunstancias personales y de contexto del infractor, y pueda ponderar, de conformidad con los principios que rigen el debido proceso, el non bis in idem y también de acuerdo con la sana crítica, la verdadera necesidad punitiva y resocializadora de aplicar al infractor una sanción de suspensión o cancelación de licencia por acumulación, sin quedar atado de manos como en la actualidad, atendida la redacción imperativa del encabezado de la norma. 


\section{Referencias}

Bustos Ramírez, Juan (2007). Derecho penal: Parte general. 2. ${ }^{a}$ ed. Santiago: Jurídica de Chile.

Cordero Quinzacara, Eduardo (2014). Derecho administrativo sancionador: Bases y principios en el derecho chileno. 1. ${ }^{\mathrm{a}}$ ed. Santiago: Legal Publishing.

Etcheberry, Alfredo (1997). Derecho penal: Parte general. $3 .^{a}$ ed. Santiago: Jurídica.

García Cavero, Percy (2016). «El principio ne bis in idem material en caso de concurrencia de pena y sanción administrativa». Política Criminal, 11 (21): 21-33. DOI: 10.4067/So718-33992016000100002.

Garrido Montt, Mario (2007). Derecho penal: Parte general. Tomo 1. 2. ${ }^{\mathrm{a}}$ ed. Santiago: Jurídica de Chile.

Gómez GonzÁlez, Rosa Fernanda (2017). «El non bis in idem en el derecho administrativo sancionador: Revisión de sus alcances en la jurisprudencia administrativa». Revista de Derecho de la Pontificia Universidad Católica de Valparaíso, 49: 101-138. DOI: 10.4067/So718-68512017000200101.

Instituto Libertad y Desarrollo (2015). Actualización del proyecto de Ley que modifica la Ley 18.290 en lo relativo a la obtención de licencias de conducir. Boletín 2504. Reseña Legislativa. Chile.

MaÑalich, Juan Pablo (2014). «El principio ne bis in idem frente a la superposición del derecho penal y el derecho administrativo sancionador». Política Criminal, 9 (18): 543-563. DOI: 10.4067/So718-33992014000200008.

MARINA JALVo, Belén (2003). «La problemática solución de la concurrencia de sanciones administrativas y penales: Nueva doctrina constitucional sobre el principio non bis in idem». Revista de Administración Pública, 162: 175-188. Disponible en http:// bit.ly/2RiZouy.

Nogueira Alcalá, Humberto (2010). Derechos fundamentales y garantías constitucionales. Tomo 1. Santiago: Librotecnia.

Nuño Jiménez, Irene y Francisco Puerta Seguido (2016). «Derecho administrativo sancionador. Principios de la potestad sancionadora». Gabilez: Revista del Gabinete Jurídico de Castilla-La Mancha, 5: 142-19o. Disponible en http://bit.ly/2RjSYtl.

Ramírez Torrado, María Lourdes (2013). «El non bis in idem en el ámbito administrativo sancionador». Revista de Derecho de la Universidad del Norte, 40: 1-29. Disponible en http://bit.ly/2Rg3cLi.

\section{Sobre el autor}

Rodrigo Alejandro Henríquez Figueroa es abogado. Licenciado en Ciencias Jurídicas y Sociales de la Pontificia Universidad Católica de Valparaíso, Chile. Es diplomado en Litigación en Derecho Administrativo Sancionador de la Facultad de Derecho de la Universidad de Chile y ejerce como secretario abogado y juez de Policía Local subrogante del Juzgado de Policía Local de Renca. Su correo electrónico es rodrigo. henriquez.pucv@gmail.com. 
